\title{
Perceived ethical values of Malaysian managers
}

\begin{abstract}
This paper examines the perceived ethical values of Malaysian managers. It is based on the opinions of 15 hypothetical ethical/unethical business situations from the 81 managers who agreed to participate in the survey. The findings of this study showed that these Malaysian managers have high ethical values. However $53 \%$ of the respondents believed that the ethical standards of today are lower than that of 15 years ago. Apparently, this is related to the existence of many unethical business practices prevalent in the modern business world. The behavior of one's immediate superior is the most important factor in influencing managers to commit unethical practices. The results also indicate only a slight variation among the managers in terms of perceived ethical values by virtue of job position, job specialization, type of business activity or the size of the business organization.
\end{abstract}

Keyword: Ethical values; Mangers; Malaysia 